\title{
Written Corrective Feedback Given to Errors in Sentence Structure: A Case Study
}

\author{
Gunady, Fabiola \\ English Department, Faculty of Letters, Petra Christian University \\ Siwalankerto 121-131, Surabaya, East Java, Indonesia \\ E-mail: fabiolagunady@rocketmail.com
}

\begin{abstract}
This study is done to find out the types of written corrective feedback related to errors in sentence structure given by the teacher of Writing 2 class and the types of sentence structure errors that have written corrective feedback. In this study, I used two theories: a typology of written corrective feedback types proposed by Ellis (2009) and exploring errors in grammar proposed by Ho (2005). This research used qualitative approach. The source of data was 23 students' original drafts after the midterm exam and the data are teacher's written corrective feedback found in the students' original drafts and sentence structure errors that have written corrective feedback. The findings of this study showed that there were three types of written corrective feedback found in the students' original drafts, namely: Direct Corrective Feedback, Indirect Corrective Feedback, and Reformulation and there were five types of sentence structure errors found in the students' original drafts, namely: Fragmented sentence, Run-on sentence, Inappropriate coordinating conjunction, Inappropriate subordinating conjunction, and Misordering or Inversion of subject-verb.
\end{abstract}

Key words: feedback, written corrective feedback, sentence structure

\section{INTRODUCTION}

Feedback can be defined as an input from a reader to a writer that provides information for revision (Keh, 1990, p. 294). Generally, feedback provides information for teachers and students. Through feedback, teachers can evaluate their own teaching and know the students' performance. For students, feedback is an ongoing assessment which focused more on progress than grades.

Written corrective feedback refers to the correction of errors and weaknesses in content, organization, and language through writing (Lewis, 2002). According to Lewis (2002, p. 4), "the purpose of written corrective feedback is to motivate. It can encourage students to study and to use language to the best of their ability by taking into account whatever teacher knows about the learners' attitudes". Feedback becomes an important aspect in the writing process since it can help the students to develop their writing skills by learning from their errors.

Based on Waishing (2000, p. 26), "Written corrective feedback is the most common feedback delivering method for both teachers and students and which contributes to the overall improvement of student writing be it at form or content level". Besides, "Many teachers feel they must write substantial comments on papers to provide a reader reaction to students' efforts, to help them improve as writers and to justify the grade they have been given" (Hyland, 2003, p. 84). Considering both Waishing's and Hyland's opinion, I think written corrective feedback is quite necessary. Therefore, I focus this research on written corrective feedback on students' assignment in writing 2 class.

Based on the catalogue of English Department in Petra Christian University (2016, p. 15), Writing 2 class aims "to enable the students to write well descriptive and narrative essays in terms of topic sentence (clear and specific), content (well-developed), organization (logic, cohesive, coherent), and language (correct grammar and vocabulary)". In this current class 2016/2017, there were twelve students taking Writing 2 class. The writing teacher (after the midterm exam) assigned the students to finish two essays and attend ten class meetings. Students had to write 400-450 words for each essay.

Each assignment had one draft (an original draft which later the teacher gave written corrective feedback) and the final version. In this study, I focus on the original draft because it shows the 
originality of students' writing draft. In writing 2 class, the students wrote the original draft, then they submitted it to the teacher. The teacher gave comments/written corrective feedback on the students' original drafts.

This research focuses on finding (1) the types of written corrective feedback that the teacher of Writing 2 class gives to errors in sentence structure and (2) the types of sentence structure errors that have written corrective feedback.

\section{Types of Written Corrective Feedback Strategies}

There are six strategies of written corrective feedback types by Ellis (2009), namely Direct Corrective Feedback, Indirect Corrective Feedback, Reformulation, Metalinguistic Corrective Feedback, Focused and Unfocused Corrective Feedback, and Electronic Feedback.

1. Direct Corrective Feedback: It provides the correct form from the teacher to the student. This can be done by crossing out an unnecessary word, phrase, or morpheme; inserting a missing word or morpheme; and writing the correct form above or near the incorrect form (Ellis, 2009 p. 99). For example:

a $\quad \mathrm{a}$

"A $\operatorname{dog}$ stole $\wedge$ bone from $\wedge$ butcher".

2. Indirect Corrective Feedback: It shows that the students make an error but the teacher does not provide any correction. In other words, the teacher asks the students to identify and correct it themselves. This can be done by underlining, circling the errors, and giving upper case " $\mathrm{X}$ " to show the omissions in the student's text (Ellis, 2009 p. 100). For example:

"A dog stole X bone from X butcher. He escaped with XhavingXX bone".

$\mathrm{X}=$ missing word

$\mathrm{X} \quad \mathrm{X}=$ wrong word

Indirect corrective feedback has two types: coded indirect feedback and uncoded indirect feedback. In the first type, coded indirect feedback, the teacher determines the type of errors (for example, "verb tense" or "spelling"). In the second type, uncoded indirect feedback, the teacher underlines or circles the errors and does not write the correct answer to indicate the errors.

3. Reformulation: It consists of a native speaker's reworking of the students' entire text to make the language seem as native- like as possible. Reformulation involves two options 'direct correction' (the teacher corrects the errors directly and makes the language seem like the native speaker's language) and 'revision' (the students change the words or the sentences from native correction). For example:

Original version:

"As he was jogging, his tammy was shaked".

Reformulation:

"As he was jogging, his tummy was shaking".

Error correction:

"As he was jogging his tammy was shaked". tummy shaking

4. Metalinguistic Corrective Feedback: It provides codes ("ww" for wrong word, "art" for article) to show the students' errors. According to Ho (2005), it is better to indicate to students the type of errors made, using a code of symbols, and then allow them to correct the errors themselves. By doing so, students are familiar with the codes that the teachers use when they edit or mark their work. Besides, Ferris and Roberts (2001) found that error codes help the students to edit their writing by themselves. However, metalinguistic corrective feedback is not more effective than indirect feedback. The example of this type of written corrective feedback:

art. art.

"A dog stole bone from butcher".

5. Focused and Unfocused Corrective Feedback: A teacher requires selecting specific error types for correction, such as s/he only gives feedback to students in verb usage. In unfocused corrective 
feedback

however, teacher can choose to give feedback in many kinds of errors (in language use, vocabulary, content). Sheen's theory (2007) as cited in Ellis (2009) states that there are two types of focused versus unfocused corrective feedback: focused direct feedback and unfocused direct feedback. The first type, the focused direct feedback, is a form of direct feedback which the teacher only indicates and corrects the errors in the specific linguistic feature such as article "a" and "the", verb form, or preposition. The second type, the unfocused direct feedback, is implemented when the teacher indicates and corrects all errors in the students' text.

6. Electronic Feedback: It occurs when the teacher gives comments to the students' work and provides examples of the correct usage. The comments can be given through e-mail, text editing programs, web-based editing services, and other software programs. This feedback provides a brief comment on each error and shows the correct form. It requires the students to correct the errors themselves.

\section{Types of Sentence Structure Errors}

There are eight types of sentence structure errors namely: dangling modifier, squinting modifier, jumbled-up or illogical sentence, incomplete or fragmented sentence, run-on sentence, inappropriate coordinating conjunction, inappropriate subordinating conjunction, and misordering or inversion of subject-verb (Ho, 2005).

1. Dangling Modifier: A sentence which is not clearly stated and need to be modified. In other words, the subject of the main clause is omitted. Ho (p. 73) gives an example below:

- "Having got all the support of students, the project was launched".

This sentence is incorrect because 'Having got all the support of students' is a participial phrase expressing action but 'the project' is not the subject of the main clause: 'The project' cannot get the support of 'the students'. As the subject of the main clause expressed in the participial phrase has not been clearly stated, the participial phrase is termed a dangling modifier.

- "Having got all the support of the students, the principal launched the project".

This sentence is correct because the subject of the main clause is stated: 'the principal'. Logically, he is the person who must be doing the action expressed in the participial phrase 'Having got all the support of students'. Therefore, the sentence does not have a 'dangling modifier'.

2. Squinting Modifier: It occurs when the phrase has been split up unnecessarily so the words that modify are not clear. Ho (p. 73) gives an example below:

- "The problem has been brought up to the discipline master of the notorious student in class".

This sentence is incorrect because the nominal phrase 'the problem of the notorious student in class' is broken up, at different points within the sentence, into two separate phrases 'the problem' and 'of the notorious student in class', it is not clear what the word modified i.e. 'the problem' is.

- "The problem of the notorious student in class has been brought up to the discipline master".

This sentence is correct because the subject of the sentence is 'the problem of the notorious student in class' which has been 'brought up to the discipline master'. It is clearly stated that the phrase 'of the notorious student in class' modifies the word 'the problem'.

3. Jumbled-up or Illogical Sentence: It arises when there is an illogical or jumbled-up ordering of clauses. It is linked by the coordinating conjunction and needs to be re-arranged. Thus, the sentence can be logical or make sense. Ho (p. 74) gives an example below:

- "The child went to see the doctor so the child had a bad stomach ache".

This sentence is incorrect because it means after the child went to the doctor the child had a bad stomach ache. It is not logical.

- "The child had a bad stomach ache so s/he (the child) went to see the doctor".

This sentence is correct because it is logical. The consequence of the child having a bad stomach ache is his or her going 'to see the doctor'. Thus, the clause 's/he (the child) went to see the doctor' is linked to the initial clause 'The child had a bad stomach ache' after the use of the conjunction 'so'. 
4. Incomplete or Fragmented Sentence: A subordinate clause that stands by its own. Whereas a subordinate clause cannot stand by its own, it should be linked to the main clause. Ho (pp. 74-75) gives an example below:

- "Although she was sick. She went to the concert to support her classmates".

This sentence is incorrect because 'Although she was sick' is a subordinate clause and cannot stand on its own. It should be linked to the main clause 'she went to the concert to support her classmates' to make a complete sentence.

- "Although she was sick, she went to the concert to support her classmates".

This sentence is correct because it is linked to the main clause.

According to Hogan (2012), a complete sentence must contain both a subject and a verb. Fragmented sentence is an incomplete sentence that does not make sense and cannot stand on its own. It is also a sentence that does not have a subject, a verb, both subject and verb, and a helping verb. Hogan (2012, p. 201) gives some examples below:

- "Can't be my friend".

This sentence is incorrect because it does not have a subject. It should be revised by adding a subject.

- "Tom can't be my friend".

This sentence is correct because it has a subject. Tom is the subject of the sentence.

5. Run-on Sentence: It has two independent clauses which are joined together with no connecting word to separate the clause. Ho

(p. 75) gives some examples below:

- "I didn't know which CCA I should join I was too confused by all the options".

This sentence is a run-on sentence. The clauses 'I didn't know which CCA I should join' and 'I was too confused by all the options' are combined without any conjunction.

- "I didn't know which CCA I should join as I was too confused by all the options". The two clauses above should be combined by using the coordinating conjunction 'as'.

- "I didn't know which CCA I should join; I was too confused by all the options". In this example, the two clauses are combined by using a semi-colon (;).

6. Inappropriate Coordinating Conjunction: A compound sentence that consists of coordinate clauses which are linked by an inappropriate coordinating conjunction. Ho (p. 76) gives an example below:

- "I can't decide whether Mei Ling and Bee Leng should be the only girl to represent our class". This sentence is incorrect because the use of the conjunction is not appropriate.

- "I can't decide whether Mei Ling or Bee Leng should be the only girl to represent our class". This sentence is correct because two choices posed to the speaker in deciding who the "only girl' is. The conjunction 'or' is used to show the alternative options available.

7. Inappropriate Subordinating Conjunction: A complex sentence that consists of subordinate clauses which are linked by an inappropriate subordinating conjunction. Ho (p. 76) gives an example below:

- "They did not inform her of the outcome unless they did not want to disappoint her". This sentence is incorrect because the word 'unless' is used as an exception.

- "They did not inform her of the outcome as they did not want to disappoint her". This sentence is correct because the subordinate clause provides the reason or the cause for the action in the main clause, which is, not informing her. Hence, the subordinating conjunction 'as' is required to link the sentence 'they did not inform her of the outcome' to 'they did not want to disappoint her'.

8. Misordering or Inversion of Subject-Verb: It occurs when the location of a subject and a verb is not suitable. In a direct question format, the verb comes before a subject. Besides, in an indirect question format, the subject comes before a verb. Ho (p. 77) gives some examples:

In a direct question format, the verb comes before a subject: 
"Why are we taught this?"

$$
\mathrm{V} \mathrm{S}
$$

In an indirect question format as where there is a question embedded in another question, the subject comes before a verb:

"Do you know why we are taught this?"

\section{$\mathrm{S} \mathrm{V}$}

If the subject does not come before a verb in an indirect question format, there is a misordering or inversion of the subject and verb:

"Now I don't know why are we taught this".

$$
\mathrm{V} \mathrm{S}
$$

The theories of Ellis (2009) and Ho (2005) are used as a guideline to help me categorize the types of teacher's written corrective feedback and the types of sentence structure errors having the written corrective feedback to support my analysis of this research.

\section{METHOD}

This study used qualitative approach. The source of data was the students' original drafts. The data of the study were the sentences that contain teacher's written corrective feedback given to errors in sentence structure. However, I do not analyze teacher's written corrective feedback which is unrelated to sentence structure errors, for instance: verb forms, articles, prepositions, and etcetera. I collected the data by asking permission from the lecturers and the students of Writing 2 class and copied the students' original drafts. In Writing 2 class, there were 12 students. Each student had the original draft and the final revision. I took the original draft from each assignment. One draft consisted of 400-450 words. Thus, the total number of the original drafts that I analyzed was 24 (12 students $\mathrm{x} 2$ assignments). However, one data was missing when I did my progress report in October 2017. I took the data from October 2016 up to December 2016.

I started to read the students' original draft and identified the written corrective feedback given to errors in sentence structure. Then, I marked the written corrective feedback using bold letters. Next, I underlined the sentence structure errors using red ink ( ... ) and put numbers in the upper right sentence as a mark if the sentence is wrong. Each error that the students made in their original draft was counted as one mistake. If, for example, there are two run-on sentences in the students' original draft, I counted them as two mistakes.

After identifying the written corrective feedback given to errors in sentence structure, I categorized the types of written corrective feedback. The analysis was based on the theory presented by Ellis (2009).

\section{FINDINGS AND DISCUSSION}

The types of written corrective feedback which are given to errors in sentence structure in the students' original drafts of the first and second assignments on the second topic are presented in Table 1. From Table 1, I found that from six types of written corrective feedback proposed by Ellis (2009), the teacher only used three types of written corrective feedback: Direct Corrective Feedback, Indirect Corrective Feedback, and Reformulation.

\begin{tabular}{|c|c|c|c|}
\hline $\begin{array}{c}\text { Types of Written Corrective } \\
\text { Feedback Used by the } \\
\text { Teacher }\end{array}$ & $\begin{array}{c}1^{\text {st }} \\
\text { Assignment }\end{array}$ & $\begin{array}{c}2^{\text {nd }} \\
\text { Assignment }\end{array}$ & $\begin{array}{c}\text { Total of Written } \\
\text { Corrective Feedback }\end{array}$ \\
\hline Direct Corrective Feedback & 5 & 4 & 9 \\
\hline Indirect Corrective Feedback & 6 & 8 & 14 \\
\hline Reformulation & 1 & - & 1 \\
\hline $\begin{array}{l}\text { Metalinguistic Corrective } \\
\text { Feedback }\end{array}$ & - & - & - \\
\hline Focused and Unfocused & - & - & - \\
\hline
\end{tabular}

Table 1. The Types of Written Corrective Feedback Used by the Teacher 
Corrective Feedback

Electronic Feedback

Table 1 was made to answer the first research question about the types of written corrective feedback that the teacher of Writing 2 class gives to errors in sentence structure. From the table above, it can be seen that Indirect Corrective Feedback was the most frequently used by the teacher.

\section{Direct Corrective Feedback}

Direct corrective feedback provides the correct form by crossing out an unnecessary word, phrase, or morpheme, inserting a missing word or morpheme, and writing the correct form above or near the incorrect form. There are some examples from the students' original drafts:

a. My brother tried to avoid them. But they drove their motorcycle very fast.

Based on this data, the students' original draft consisted of two separate parts: 1) My brother tried to avoid them and 2) But they drove their motorcycle very fast. Then, the teacher gave the correct form by putting a comma to combine the parts into one.

b. My brother punched the motorcycle and his left foot be pinned under knalpot whereas me flunged

away far from my brother.

Based on this data, the teacher gave the correct form by putting a comma before the word "whereas" to combine the sentences and inserting an auxiliary verb "was" before the word "flunged" to make the sentence complete.

\section{Indirect Corrective Feedback}

Indirect corrective feedback does not provide any correction. Based on the theory (Ho, 2005), there are two types of Indirect Corrective Feedback: Coded and Uncoded Indirect Corrective Feedback. These two types could be found in the findings of this research.

a. Coded Indirect Corrective Feedback

In this research, the teacher wrote "run-on" as the coded indirect corrective feedback. The coded indirect corrective feedback can be seen below:

a. I wanted scream to ask help from my parents but my voice could not came out, I was really scared

until I could not do anything.

run-on

Based on this data, the teacher underlined the words "out" and "I" and wrote "run-on" below. It means that the sentence should be revised.

b. I couldn't wait to explore Europe, I even didn't want to take a rest for a while.

$$
\text { run-on }
$$

Based on this data, the teacher underlined the words "Europe" and "I" and wrote "run-on" to show that it should be revised.

\section{b. Uncoded Indirect Corrective Feedback}

In this research, the uncoded indirect corrective feedback found is using circle, underline, and symbol. The uncoded indirect corrective feedback can be seen below:

\section{By Giving a Circle}

This one came from one particular moment in my life when I heard and knew my best friend that was dec

Based made me afraid

before the phrase to show that there is something missing.

By Underlining

Snake still a dangerous creature who has a lot of deadly weapons.

Based on the data above, the teacher underlined the word "who" which is not suitable with the subject "Snake". However, the teacher did not write anything.

\section{By Giving a Symbol}


There are two kinds of symbols used in the students' original drafts: parentheses "(...)" and symbol " $\Lambda$ ".

Many people will probably say their most frightening experience was meeting ghost or near-death experience, (not so for me).

Based on this data, the teacher gave parentheses to the phrase "not so for me" to show that the word "so" did not match with the sentence.

\section{Reformulation}

Reformulation consists of a native speaker's reworking of the students' entire text to make the language seem as native-like as possible. Therefore, in student's work, teacher writes all the correct sentences. There is one example from the students' original drafts:

I did not know what should I do.

Based on this data, the teacher rewrote the entire correct sentence at the end of the paragraph to show that there is something wrong with the sentence.

\section{The Types of Sentence Structure Errors that Have Written Corrective Feedback}

The types of sentence structure errors that have written corrective feedback in the first and second assignments on the second topic are presented in Table 2.

Table 2. The Types of Sentence Structure Errors Found in the Students' Original Drafts

\begin{tabular}{l|c|c|c}
\multicolumn{1}{c}{ Sentence Structure Errors } & $1^{\text {st }}$ Assignment & $\begin{array}{c}2^{\text {nd }} \\
\text { Assignment }\end{array}$ & $\begin{array}{c}\text { Total of Sentence } \\
\text { Structure Errors }\end{array}$ \\
\hline Dangling Modifier & - & - & - \\
Squinting Modifier & - & - & - \\
Illogical Sentence & - & - & - \\
Fragmented Sentence & 7 & 10 & 17 \\
Run-on Sentence & 2 & 2 & 4 \\
Coordinating Conjunction & 1 & - & 1 \\
Subordinating Conjunction & 1 & - & 1 \\
Misordering & 2 & - & 2 \\
\hline
\end{tabular}

From Table 2, I found that from eight types of sentence structure errors proposed by Ho (2005), the students only made five types of sentence structure errors that are appeared in their original drafts: Fragmented Sentence, Run-on Sentence, Coordinating Conjunction, Subordinating Conjunction and Misordering.

Table 2 was made to answer the second research question about the types of sentence structure errors that have written corrective feedback in the first and second assignments on the second topic. From Table 2, it can be seen that Fragmented sentence was the most common error found in the students' original drafts.

\section{Fragmented Sentence}

Fragmented sentence is a subordinate clause that stands by its own. However, a subordinate clause cannot stand by its own because it is not complete yet. It should be linked to the main clause. A fragment does not have a subject, a verb, both subject and verb or a helping verb. There are some examples from the students' original drafts:

Snake still a dangerous creature who has a lot of deadly weapons.

This data is considered as fragmented sentence because there is no verb after the word "Snake". A complete sentence should have a subject and verb. That is why, the verb "is" should be added. The word "still" is eliminated because it is not appropriate in the sentence. The correct sentence should be: Snake is a dangerous creature that has a lot of deadly weapons.

\section{Run-on Sentence}

Run-on sentence has two independent clauses which are joined together with no connecting word to separate the clause. There are some examples from the students' original drafts: 
This one came from one particular moment in my life when I heard and knew my best friend that was dead made me afraid.

This data is considered as run-on sentence because in the sentence, there is no conjunction to combine the clause "when I heard and knew my best friend that was dead" and the phrase "made me afraid". There should be a semicolon (;) because it can be used as a conjunction. Therefore, the correct sentence should be: This one came from one particular moment in my life when I heard and knew my best friend that was dead; it made me afraid.

\section{Inappropriate Coordinating Conjunction}

Inappropriate coordinating conjunction is a word that is used in a compound sentence that consists of coordinate clauses which are linked by an inappropriate coordinating conjunction. There is one example from the students' original drafts:

Many people will probably say their most frightening experience was meeting ghosts or near-death experience, not so for me.

This data is considered as having an inappropriate coordinating conjunction because the conjunction "so" is not appropriate. The conjunction "so" is used to show the effect of something. It is more appropriate to use the conjunction "but" in this data because the word "not" shows opposition or contrast. The correct sentence should be: Many people will probably say their most frightening experience was meeting ghosts or near-death experience, but not for me.

\section{Inappropriate Subordinating Conjunction}

Inappropriate subordinating conjunction is a word that is used in a complex sentence that consists of subordinate clauses which are linked by an inappropriate subordinating conjunction. There is one example from the students' original drafts:

Snake still a dangerous creature who has a lot of deadly weapons.

This data is considered as having an inappropriate subordinating conjunction because the conjunction "who" is not appropriate with the subject "Snake". Snake is an animal, so the right conjunction should be "that" or "which". The conjunction "who" is used for people. Therefore, the correct sentence should be: Snake is a dangerous creature that has a lot of deadly weapons.

\section{Misordering or Inversion of Subject-Verb}

Misordering occurs when the location of a subject and a verb is not suitable. There are two examples from the students' original drafts:

I called my parents and they said, "why you are so careless about your own important things?"

This data is considered as misordering because the subject and verb in the direct question "why you are so careless about your own important things?" should be inverted. As Ho (2005) stated, in a direct question format, the verb comes before the subject. The correct sentence should be: I called my parents and they said, "why are you so careless about your own important things?"

\section{CONCLUSION}

This study focuses on written corrective feedback given to errors in sentence structure. By conducting this study, I would like to find out the types of written corrective feedback that the teacher of Writing 2 class gives to errors in sentence structure and the types of sentence structure errors that have written corrective feedback. In order to answer those two research questions, I used two theories, namely: a typology of written corrective feedback types proposed by Ellis (2009) and exploring errors in grammar proposed by Ho (2005). This research used qualitative approach.

Based on the analysis of twenty four students' original drafts, the findings showed that from six types of written corrective feedback, there were only three types of written corrective feedback found in the students' original drafts. They were Direct Corrective Feedback, Indirect Corrective Feedback, and Reformulation. Indirect Corrective Feedback was used by the teacher more than the other types of written corrective feedback (14 times). The findings also showed that from eight types of sentence structure errors, there were only five types of sentence structure errors found in the students' original drafts. They were Fragmented Sentence, Run-on Sentence, Inappropriate Coordinating Conjunction, Inappropriate Subordinating Conjunction, and Misordering or Inversion 
of Subject-Verb. Fragmented Sentence was the most common error found in the students' original drafts and it had the highest numbers, that is, 17 Fragmented Sentence.

In conclusion, most of the students still have difficulties in constructing complete sentences. Because the teacher used indirect corrective feedback more frequently, it can be concluded that indirectly the teacher wanted the students to find out the errors by themselves so that they will learn and understand their errors.

\section{REFERENCES}

English Department. (2016). Curriculum English Department, PCU. Retrieved September 26, 2016 from http://inggris.petra.ac.id/assets/Main/ED-Courses-Description-040112.pdf

Ellis, R. (2009). A typology of written corrective feedback types. ELT Journal, 63(2), 97-107.

Ferris, D. R. \& Roberts, B. (2001). 'Error feedback in L2 writing classes: How explicit does it need to be?'. Journal of Second Language Writing 10: 161-184.

Ho, C. M. L. (2005). Sentence Structure. In Exploring Errors in Grammar. (Second ed.). Singapore: Pearson Education South Asia Pte..

Hogan, G. (2012). Writing an essay. In Building Better Paragraphs (1st ed., pp. 201-202). Cengage Learning.

Hyland, K. (2003). Second language writing. New York: Cambridge University Press.

Keh, L. C. (1990). Feedback in the writing process: A model and methods for implementation. ELT Journal Volume 44 (4), 294-304. Oxford University Press.

Lewis, M. (2002). Giving Feedback in Language Classes. Singapore: SEAMEO Regional Language Centre.

Waishing, L. (2000). Students' Response to Teachers' Feedback on Writing: The case of third-year l.m.d students of English. Retrieved December 14, 2016 from http://bu.umc.edu.dz/theses/anglais/MAH1104.pdf 